\title{
A MODULAÇÃO DO DISCURSO DO RADIOJORNALISMO DIANTE DA INTERNET
}

THE MODULATION OF THE SPEECHOF RADIOJORNALISM IN THE

INTERNET

\author{
Alvaro Bufarah JúNIOR ${ }^{1}$ \\ Universidade Presbiteriana Mackenzie | Brasil
}

\begin{abstract}
Resumo
O meio rádio teve suas características ampliadas e potencializadas pela internet, possibilitando uma diferenciação de seus conteúdos por meio de uma alteração na produção, edição e transmissão, e ganhando mais agilidade com a digitalização do áudio e demais informações necessárias para atender a um público com mais poder de escolha. Essas mudanças levaram a alterações profundas no formato das narrativas, que evoluíram para ter maior proximidade com o público, deixando de ser uma comunicação mais formal para ser mais informal, baseada na coloquialidade e com forte influência das redes sociais. Este texto traz algumas considerações sobre as variáveis de modulação entre a fala e a escrita no radiojornalismo após o advento da internet.

\section{Palavras-chave}

Radiojornalismo; discurso; narrativa; internet; notícia.

\section{Abstract}

The media radio had its characteristics expanded and enhanced by the internet, making it possible to differentiate its contents through a change in production, editing and transmission, and gaining more agility with the digitization of audio and other information necessary to serve an audience with more power of choice. These changes led to profound changes in the format of the narratives, which have evolved to be closer to the public, moving from being more formal communication to being more informal, based on colloquiality and with a strong influence of social networks. This text brings some considerations about the modulation variables between speech and writing in radiojournalism after the advent of the internet.

\section{Keywords}

Radiojournalism; discourse; narrative; internet; news.
\end{abstract}

\section{RECEBIDO EM 22 DE MARÇO DE 2020}

ACEITO EM 11 DE MAIO DE 2020

${ }^{1}$ Doutor pelo programa de Letras da Universidade Presbiteriana Mackenzie, Pós-doutorando do programa de Pós-Graduação em Jornalismo da Universidade Federal de Santa Catarina e integrante do Grupo de Investigação em Rádio, Fonografia e Áudio (Girafa) no mesmo programa. Contato: abufarah@uol.com.br.

João Pessoa - Brasil | ANO 7, VOL. 7, N. 1 | JAN./JUN. 2020 | p. 87-104 


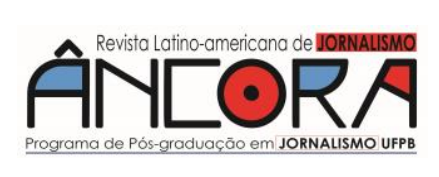

\section{Alvaro Bufarah JÚNIOR}

\section{Introdução}

ara Lage (2005, p. 73), o que caracteriza o texto jornalístico e o que o
diferencia dos demais é o volume de informações factuais resultantes
da apuração e dos tratamentos dos dados, que têm o objetivo informar e não convencer. $O$ autor complementa que a base do texto jornalístico é a notícia, que é a exposição de um ou mais fatos novos ou desconhecidos do mesmo evento com suas circunstâncias. Neiva (2013, p. 401) conceitua esse fato como o "relato de fatos e acontecimentos, recentes ou atuais, ocorridos no país ou no mundo, veiculado em um meio de comunicação e o assunto tema deste relato". Muitos autores utilizam o conceito de notícia como sinônimo de informação, porém, devemos diferenciar ambos conceitos. Para este estudo, utilizaremos a definição de Neiva (2013, p. 205), para quem a informação é "conhecimento ou fato de interesse geral, tornado de conhecimento público ao ser divulgado pelos meios de comunicação". Portanto, podemos afirmar, com base nos conceitos expostos, que a notícia contém informações necessárias para serem apresentadas ao público, sendo ela o conteúdo produzido, editado e entregue ao consumidor.

Ortriwano (1985, p. 90) amplia o conceito de notícia quanto à sua estruturação ao afirmar que é permitido encarar a notícia como algo que se constitui de dois componentes básicos: a) uma organização estável, ou componente lógico; b) elementos escolhidos segundo critérios de valor essencialmente cambiáveis que se organizam na notícia (o componente ideológico). Dessa forma, a autora considera notícia a base de toda a atuação informativa, dependendo do tratamento que recebe na elaboração da mensagem. Meditsch (1999, p. 275) propõe uma abordagem diferenciada para o discurso do radiojornalismo, em que afirma que a notícia no meio radiofônico não transmite apenas a realidade, mas cria a representação sobre ela, em que se manifestam não apenas o referencial de realidade, como também a subjetividade de seus produtores e a intersubjetividade de sua inserção social, 
idiossincrasias pessoais, valores e saberes profissionais, constrangimentos, orientações organizacionais etc., e determinações históricas e culturais que estabelecem as possibilidades e os limites de abordagem da realidade operada pela rádio informativa.

O autor indica que, embora a informação trazida pelo jornalismo seja a mesma que está nos diversos meios, no rádio, há uma série de diferenças pontuais que configuram especificidades da notícia, que estabelecem uma relação com a natureza eletrônica do meio, que, por sua vez, difere dos discursos da oralidade da comunicação imediata da vida cotidiana e da escrita.

Para Meditsch (1999, p. 276-277), a forma do discurso no meio rádio tem como padrão diferencial o suporte material auditivo e sua condição de invisibilidade, que estabelecem características únicas ao formato da linguagem que, por sua vez, teve seu uso condicionado devido às limitações do meio e às adaptações trazidas do jornalismo impresso (antecessor do rádio na linha histórica de desenvolvimento dos meios). O pesquisador complementa afirmando que o gênero não ocorre no discurso, mas por meio dele, na interação social por ele possibilitada, uma vez que o conteúdo da informação radiofônica é condicionado intersubjetivamente pelo emissor e pela audiência (auditório) a que se destina, e a amplitude dessa audiência e sua posição social também condicionam a forma de construção da realidade da mensagem informativa radiofônica.

Para Angel Faus Belau (1981, p. 169), o produto sonoro radiofônico vai além das estruturas condicionantes do programa inserido na programação de uma emissora, para assumir uma dimensão ampla, marcada pela intencionalidade da produção de um conteúdo específico que condiciona a mensagem a ser enviada. Dessa forma, esse produto diferencia-se pelos seus atributos técnicos e psicológicos dentro do espectro das comunicações humanas. 


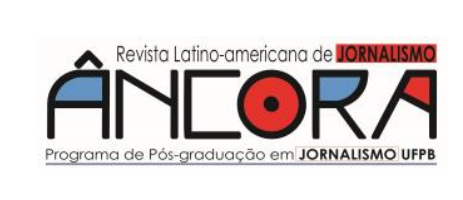

\section{Alvaro Bufarah JÚNIOR}

O meio radiofônico encontrou no gênero jornalístico um dos seus pilares para a programação (música-esportes-notícias); isso pode ser verificado pelo fato de que no processo de segmentação das emissoras foram criadas algumas especializadas em informação. No entanto, todos os gêneros estão baseados na mesma estrutura narrativa originada nas limitações técnicas do meio.

No radiojornalismo, os textos (estruturados em roteiros) são produzidos para o melhor entendimento do público. Para tanto, o uso da voz e de outros recursos sonoros são fundamentais. No rádio, os elementos que "carregam" e organizam a informação são a voz, a oralidade, conjugada a outros signos sonoros (ruído, música), e o silêncio. A palavra propõe o conteúdo do fato transmitido, enquanto o ruído, a música e o silêncio ambientam e oferecem ao ouvinte a sensorialidade; isto é, são responsáveis por "transportar"o receptor ao "clima", ao cenário do acontecimento, proporcionando a chamada criação de imagens mentais, tão faladas quando o objeto de estudo é o meio de comunicação rádio analógico. Quando sonoplastia e texto entram em equivalência, um traço da materialidade da palavra é emprestado à sonoplastia e vice-versa. Trata-se da transmutação do verbal em sonoplastia (efeito sonoro e trilha) e da sonoplastia em verbal em um processo de equivalência e justaposição de sentidos, em que paralelismo e simultaneidade se equilibram (SILVA, 1999, p. 81).

Armand Balsebre (2000, p. 27) define o sistema semiótico radiofônico como um conjunto de formas sonoras e não sonoras representadas por sistemas expressivos da palavra, da música, dos efeitos sonoros e do silêndo, cuja significação vem determinada pelo funcionamento conjunto desses recursos na recepção sonora e imaginativa-visual dos ouvintes.

\section{A narrativa do discurso do radiojornalismo}

Partiremos do ponto definido por Greimas (2012, apud FIORIN, 2013 p. 6), que toma o texto como a unidade de análise semântica básica, subdividida em três categorias de estudo: a gerativa, que estabelece modelos que 
apreendem os níveis de invariâncias crescentes do sentido, de tal forma que se perceba a diferenciação dos termos em diversos níveis do texto; a sintagmática, que explica a produção e a interpretação do discurso, e não apenas suas unidades lexicais; e a geral, que tem como postulado as unicidades do sentido, que pode ser manifestada por diferentes planos de expressão.

Para tanto, Greimas indica em sua teoria do discurso que a sintaxe contrapõe a semântica, e a sintaxe dos diferentes níveis do percurso gerativo é de ordem relacional, ou seja, é um conjunto de regras que rege o encadeamento das formas de conteúdo na sucessão do discurso (apud FIORIN, 2013, p. 21).

A semântica do nível fundamental abriga as categorias que estão na base da construção de um texto, sendo estabelecidas pela diferença e na oposição entre os termos. No entanto, para que esses termos possam ser antagônicos, eles devem ter uma relação entre si, um traço comum que permita estabelecer uma diferença entre eles. Sendo assim, termos opostos de uma categoria semântica mantêm entre si uma relação de contrariedade, tendo como premissa o fato de que são contrários aos termos que estão em uma relação de pressuposição recíproca. A semântica e a sintaxe do nível fundamental representam a instância inicial do percurso gerativo e procuram explicar os níveis mais abstratos da produção, do funcionamento e da interpretação do discurso.

Os textos são narrativas complexas em que uma série de enunciados são organizados hierarquicamente para dar a impressão de sentido. Esse conjunto contém o nível discursivo, queé marcado pelas formas abstratas do nível narrativo, revestidas de termos que Ihe dão concretude. Então, a sintaxe discursiva ocorre quando os esquemas são assumidos pelo sujeito da enunciação, que converte o discurso, sendo a enunciação o ato de produção do discurso em uma instância pressuposta pelo enunciado (produto da 


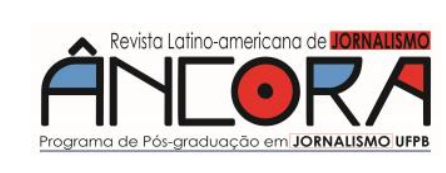

\section{Alvaro Bufarah JÚ NIOR}

enunciação). Ao ser produzida, deixa marcas no discurso que constrói, e, mesmo quando os elementos da enunciação não aparecem no enunciado, ocorre a enunciação, pois não existe frase que seja enunciada sozinha. Nesse ponto de vista, há sempre um "eu" que diz para um "tu" projetado no enunciado no "aqui" e no "agora". Dessa forma, o eu e o tu são actantes da enunciação e participantes da ação enunciativa. Quando podemos identificar essas marcas no enunciado, dizemos que o discurso é enunciativo, e quando não identificamos, afirmamos que o discurso é enuncivo. No caso dos discursos jornalísticos, o enunciador é o autor do texto (eu) que escreve para uma audiência (ouvintes = tu, no caso do rádio) em um momento marcado pelo instante da realização do fato que está sendo narrado.

Por sua vez, a sintaxe do discurso abrange dois aspectos: as projeções da instância da enunciação no enunciado e as relações entre o enunciador e enunciatário (argumentação). Para Fiorin (2013), se a enunciação se definea partir de um eu-aqui-agora, cria-se o discurso-enunciado, em que se projeta para fora os atores do discurso, bem como suas coordenadas espaçotemporais, em que utilizamos as categorias de pessoa, espaço e tempo. Para a realização desse processo, lançamos mão de dois mecanismos básicos: a debreagem e a embreagem.

A debreagem é o mecanismo que projeta no enunciado as pessoas, 0 tempo e o espaço. Ela pode ser enunciativa, quando temos as marcas expressas no texto, ou enunciva, quando elas não estão explicitadas. Para cada uma dessas categorias há três tipos de variações: de pessoa (actancial), de espaço (espacial) e de tempo (temporal).

A debreagem enunciativa projeta no enunciado o eu-aqui-agora da enunciação, instalando no enunciado os actantes enunciativos (eu/tu), os espaços enunciativos (aqui, aí etc.) e os tempos enunciativos (presente, pretérito perfeito e futuro do presente). Já a debreagem enunciva é construída 
com o "ele", o "algum lugar" e o "então", ou seja, ocultam-se os actantes, o espaço e os tempos do enunciado (FIORIN, 2013).

As debreagens enunciativas e enuncivas produzem dois tipos de discurso básicos: o de primeira e o de terceira pessoa, em que o primeiro produz o efeito de subjetividade e o segundo, de objetividade, já que na enunciativa o "eu" se coloca dentro do discurso e a enunciva ausenta-se dele. Dessa forma, narrar em primeira ou terceira pessoa é uma opção do enunciador, que visa transmitir efeitos de aproximação ou de distanciamento dentro do discurso. Esse discurso com efeito de objetividade é a base da linguagem jornalística, pois buscar apresentar a "verdade" dos fatos narrados na matéria apresentada e é um recurso muito utilizado no texto do radiojornalismo para dar o sentido de que o enunciador (jornalista) narra a história "como absolutamente ocorreu". Dessa maneira, a construção do texto é planejada para ter marcas de espaço e tempo que revelam a urgência e a importância dos fatos para o cotidiano dos ouvintes.

Também é possível que o enunciador utilize o recurso das debreagens internas ou de segundo grau, quando estabelece novos interlocutores dentro do texto, dando voz a cada um deles, criando simulacros de diálogos. Esse recurso é muito utilizado em textos jornalísticos para dar voz às fontes de informação em entrevistas, edições e matérias que utilizam como apoio trechos dos discursos de personagens que participaram da ação ou a presenciaram.

Já no discurso indireto não há debreagem interna, pois ouvimos a voz do outro pela voz do narrador, que, por sua vez, pretende apresentar uma análise do que o outro disse. Para esse tipo de discurso, temos duas variantes básicas: a analisadora de conteúdo e a analisadora de expressão. Na primeira, o narrador apresenta o que foi dito sem uma preocupação com as curiosidades da expressão, importando somente o "objetivo". Na segunda, não tem importância o conteúdo apresentado, mas sim, as particularidades de expressão, as maneiras de dizer, focando em caracterizar o ator cujo discurso 


\section{ANLORA}

\section{Alvaro Bufarah JÚ NIOR}

é analisado. Ambos formatos podem ser reconhecidos em textos jornalísticos no rádio, quando da audição de boletins (entradas dos repórteres sem trechos de entrevistas), em que narram o que Ihes foi contado, em muitos casos incluindo detalhes das expressões físicas ou de estado de ânimo dos personagens envolvidos.

Fiorin (2013, p. 68) indica que, se nos discursos diretos, as fronteiras ficam nítidas entre a fala do narrador e da personagem, no discurso indireto, a fala do narrador invade a da personagem e ressoam duas vozes na fala do enunciador: a do narrador e da personagem. Nesse caso, no radiojornalismo, o jornalista (enunciador) faz uma triagem dos dados, hierarquizando e privilegiando o que lhe parece mais interessante para a construção da narrativa. Assim, ao entrar no ar, afirma que ouviu da fonte as informações ali apresentadas, dando caráter de isenção no texto e sentido de verdade às informações filtradas para a narrativa.

Toda estrutura narrativa pressupõe uma unidade básica formatada em um texto. Barros (2011, p. 7) define texto de duas formas, sendo a primeira 0 objeto de significação entre destinador e destinatário em um processo de comunicação, e a segunda, a caracterização como elemento inserido em ambientes culturais diferentes, contidos em uma sociedade de classes, determinado por formações ideológicas específicas, tendo como base para sua análise o contexto histórico-cultural envolvido.

O enunciado elementar da sintaxe narrativa dá-se pela relação de transitividade entre dois actantes, o sujeito e o objeto. Eles relacionam-se por meio de duas funções transitivas diferentes: a junção, a relação do sujeito com um objeto qualquer, e a transformação, momento de alteração do estado do sujeito ou do objeto na narrativa. Importante destacar que, nesse contexto, 0 sujeito da narrativa é executor das ações narradas e o objeto em questão, o objetivo pelo qual foram realizadas as ações apresentadas. No texto jornalístico 
isso fica mais claro, o sujeito da notícia éo ator dos fatos narrados, sendo que o jornalista é o enunciador (autor do texto).

As relações hierárquicas do enunciado estabelecem o programa narrativo, ou sintagma elementar da sintaxe narrativa, baseada em um enunciado de fazer que rege um enunciado de estado, integrando estados e transformações.

Importante destacar que a enunciação tem como característica a mediação entre as estruturas narrativas e discursivas, sendo reconstituídas a partir das "marcas" espalhadas no discurso. Ao analisarmos o discurso, não podemos deixar de avaliar as condições socioculturais, econômicas, políticas e estruturais que nortearam a sua construção, a partir das marcas deixadas pelo enunciador.

Ao utilizar conceitos da semiótica para a análise do discurso e da enunciação nele contido, avaliamos as diferentes projeções da enunciação utilizadas na construção do discurso. Segundo Barros (2011, p. 54), a enunciação projeta para fora de si os actantes e as coordenadas espaçotemporais do discurso, que não se confundem com o sujeito, o espaço e o tempo da enunciação, operação que denominamos desembreagem. Ou seja, o sujeito da enunciação tem uma série de opções para projetar o discurso, tendo em vista os efeitos de sentido que deseja produzir. Analisar esses processos significa verificar quais os procedimentos utilizados para construir o discurso e quais são os efeitos de sentido produzidos pelos elementos discursivos utilizados. Nesse sentido, é comum utilizarmos esse referencial teórico para avaliarmos textos ficcionais, deixando o gênero jornalístico como um conteúdo acima dessa discussão, pois é apenas a representação da verdade. No entanto, devemos ter como premissa que todo discurso procura persuadir seu destinatário de que é verdadeiro. Assim, podemos afirmar que os mecanismos discursivos buscam, por finalidade, criar a ilusão da verdade e, 


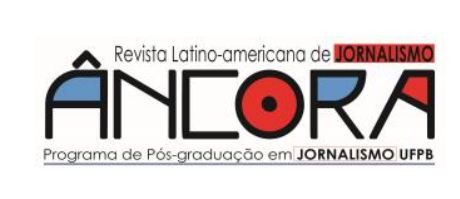

\section{Alvaro Bufarah JÚNIOR}

para tanto, utilizam dois efeitos básicos: proximidade e distanciamento da enunciação ou realidade e referente.

O primeiro conceito é facilmente percebido nos textos jornalísticos que utilizam de certa objetividade para manter a enunciação afastada do discurso como garantia de imparcialidade. Contudo, concretamente, esse processo é nada mais do que o uso de recursos para "fingir" a realidade que é fabricada pela ilusão do distanciamento, pois toda enunciação é filtrada pelos valores de seu enunciador. O principal recurso é a produção de um discurso em terceira pessoa no tempo do "então" e no espaço do "lá". Esse procedimento é denominado desembreagem enunciva. A intenção é parecer que o fato narrado é analisado com certo cientificismo de quem observa distante o ocorrido, visando neutralizar a enunciação, expondo o ponto de vista dos outros. Dessa forma, o jornalismo cria o efeito de verdade objetiva evitando arcar com a responsabilidade do que é expresso, pois transmite a opinião da fonte, e não dos profissionais ou dos meios de comunicação. Em contraposição a esse efeito, registramos a desembreagem enunciativa em primeira pessoa, em que se fabrica a impressão de subjetividade na visão dos fatos vivenciados e narrados, apresentando alto grau de parcialidade. A narrativa jornalística no meio rádio vale-se de ambos efeitos para dar a sensação de veracidade aos fatos apresentados, seja quando o repórter apresenta a matéria ao vivo, no momento do acontecimento, seja na inclusão de breves falas de personagens que servirão para dar respaldo às afirmações do conteúdo.

Os recursos da enunciação são baseados em efeitos obtidos por meio de procedimentos diversos, sendo a enunciação sempre pressuposta e nunca manifesta no texto, ela se projeta de diferentes forma e fins (BARROS, 2011, p. 57). Esse processo é apresentado na hierarquização das várias vozes dentro do discurso, sendo o narrador o delegado da enunciação no discurso de primeira pessoa. Nesse contexto, o sujeito atribui ao narrador a voz para narrar 
o discurso em seu lugar. Após assumir o controle da narrativa, o narrador pode, por sua vez, ceder inteira ou parcialmente às palavras de seus interlocutores.

Nos textos em terceira pessoa há diversos procedimentos que utilizamos para assumir a condução do discurso, entre os quais está o observador, que é como o narrador, o delegado da enunciação, mas não the cabe contar a história, tampouco determinar um ou mais pontos de vista sobre o discurso e dirigir seu desenvolvimento.

Devemos acrescentar a esse contexto a organização do saber e as relações possíveis entre os papéis do discurso e os da narrativa. Dessa forma, a enunciação distribui o saber de diferentes modos para a obtenção de efeitos diferenciados. Assim, o discurso jornalístico utiliza-se desse recurso com efeito duplo: de objetividade e de referência da verdade. 0 discurso jornalístico apresenta, de forma "imparcial", o saber de várias fontes diferentes, e o jornalista (observador) congrega o saber de todas elas para obter a verdade absoluta e ilimitada.

O efeito de realidade ou de referente apresenta-se nas ilusões discursivas de os fatos contados serem "coisas ocorridas", de os seres envolvidos serem reais, de que o discurso copia o real. Na sintaxe do discurso, os efeitos de realidade são apresentados, em geral, em desembreagens internas. Dentro do texto, apresenta-se a palavra dos interlocutores em discurso direto, em que se constrói a cena que serve de referente do texto, criando a ilusão de uma situação real de diálogo. Contudo, esses efeitos de referente (ou de realidade) são construídos, em sua maioria, por meio de procedimentos da semântica discursiva, e não da sintaxe. Nesse caso, o recurso é denominado ancoragem, em que se ata o discurso a pessoas, os espaços e as datas que o receptor reconhece como reais, preenchendo esses elementos de traços sensoriais que os "iconizam", fazendo com que finjam ser cópias da realidade. 


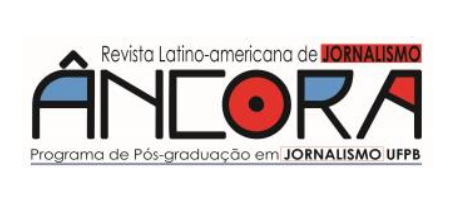

\section{Alvaro Bufarah JÚ NIOR}

A ancoragem actancial (temporal, espacial) e a delegação interna de voz são dois dos procedimentos de obtenção da ilusão de referente ou de realidade (BARROS, 2011, p. 61). Dessa forma, podemos afirmar que a estrutura da narrativa do radiojornalismo está repleta de marcas que indicam a relação de espaço e tempo como referência da narrativa, amparada pela hierarquização das vozes dentro do texto, organizadas pelo enunciador (jornalista), configurando-se como fundamental para o sentido de verdade, pressuposto básico dos textos jornalísticos.

\section{A modulação entre o tempo da fala e da escrita no radiojomalismo}

A professora Diana Luz Pessoa de Barros (2001, p. 58) apresenta uma linha de estudos coerente auxiliar a esses conceitos, uma vez que analisa a escrita e a fala como sistemas cognitivos complementares, e não paralelos ou concorrenciais. A pesquisadora examina as duas modalidades pela perspectiva de uma organização textual-discursiva em que há graus ou posiçoes intermediárias de variações entre os polos. Dessa forma, afirma que os textos falados e escritos têm papéis diferentes nas sociedades que servem, e ambos constroem sentidos em modos diversos, com estratégias e procedimentos diferentes ou preferenciais. Para tanto, as posições intermediárias entre falae escrita também são outras formas de produzir sentido nos discursos.

Barros analisa as características temporais, espaciais, actoriais do discurso falado/escrito e os traços de oralidade e sincretismo da expressão conjuntos de elementos utilizados em várias pesquisas como diferenciadores das modalidades (fala e escrita). Neste texto, utilizaremos esses referenciais teóricos desenvolvidos por Barros (2001, p. 59).

Com relação ao aspecto temporal, devemos salientar que na fala a elaboração e produção coincidem, enquanto na escrita há dois momentos diferentes: o primeiro em se elabora o texto, e o segundo em que ele é efetivamente produzido. Esse contexto indica que a concomitância, ou não, da 
elaboração e da produção decorre de três características: planejamento e não planejamento, ausência e presença de marcas de formulação e de reformulação e ainda, continuidade versus descontinuidade. Assim, separamse: a escrita planejada antes de sua realização não apresenta marcas de formulação e de reformulação e suas unidades duram mais do ponto de vista da dimensão e da complexidade, e fala não planejada antecipadamente apresenta traços de formulação e de reelaboração que assumem diferentes papéis na interação verbal e ocorre de forma fragmentada em "jatos ou borbotões"'(BARROS, 2001, p. 61).

Ao aplicarmos esses conceitos aos meios de comunicação, podemos entender que as notícias apresentadas (faladas) nos jornais de televisão e no rádio são planejadas antecipadamente por meio de textos escritos, que praticamente serão lidos com pequenas mudanças no momento de sua realização. Para que isso ocorra, o texto é estruturado de forma mais entrecortada, com unidades menores e menos complexas para facilitar o entendimento. Porém, com o uso de novos recursos tecnológicos trazidos pela revolução da informação, os textos dos meios eletrônicos passaram a ser construídos com menos tempo de apuração, sendo muitas vezes improvisados pelos apresentadores de rádio que leem e interpretam os conteúdos apresentados pelas redes sociais, agências de notícias e outros canais noticiosos disponíveis no ambiente on-line.

De toda forma, a base de produção dos noticiosos ainda é o levantamento de dados com entrevista, que têm diferentes graus de planejamento, como a preparação da pauta, a entrevista propriamente dita e a edição. Com o plano feito previamente, a entrevista tem menos marcas de elaboração e reelaboração. Contudo, há modificações na edição da fala para a escrita, uma vez que o editor altera a estrutura do conteúdo retirando hesitações e as características entrecortadas da fala que foi gravada para ser veiculada. 


\section{$\hat{A N}[\odot R A$}

\section{Alvaro Bufarah JÚ NIOR}

Devemos somar a essas características as diferenças do espaço, uma vez que as falas pressupõem um contado direto em um tempo determinado, em que as partes envolvidas utilizam recursos como gestos, expressões faciais e corporais, além de entonações das vozes. Já no texto escrito temos o destinador e destinatário centrados no mesmo espaço. Assim, o emissor lança mão de outros recursos de linguagem para complementar sua mensagem (por exemplo: falou bravo!). Portanto, não é possível assumirmos que os discursos falados e escritos produzam os mesmos efeitos de sentido. Há diferentes posições relativas ao espaço do discurso que decorrem textos diferentes, que empregam recursos e estratégias linguísticas-discursivas diversas para assegurar a comunicação e a interação entre os sujeitos envolvidos.

Outro fator diferencial é o ator na fala e na escrita, pois é o sujeito que assume papéis na organização narrativa do discurso, investidos da categoria de pessoa e preenchidos por temas e/ou figuras. Além das diferenças já reconhecidas de "falantes e ouvintes" e "escritores e leitores", temos de colocar nesse contexto temas e figuras diferentes relacionadas aos recursos distintos de expressão (sonoridade e visualidade).

Elementos que também distinguem os atores da fala e da escrita dizem respeito aos papéis narrativos que cumprem e ao investimento na categoria de pessoas. Resultantes desses conceitos, temos alguns dos traços mais comuns de individualização da fala e da escrita: a construção coletiva do texto em pelo menos duas vozes ou a quatro mãos e a alternância de papéis entre falantes e ouvintes versus a construção individual do texto (ou de uma voz)e a ausência de alternância de papéis (escritor/leitor). No meio rádio, desde seus primeiros programas, podemos registrar a participação popular por meio de telefonemas, cartas, concursos, programas de auditório etc. Ou seja, os programas radiofônicos, incluindo os jornalísticos, buscam promover essa alternância de papéis, e, após o processo de digitalização dos conteúdos, essa variação ficou mais nítida com o uso das redes sociais. 
Também temos a aproximação versus o distanciamento da enunciação dando o efeito de imparcialidade ou parcialidade, dependendo da aproximação ou distanciamento do enunciatário para com o discurso. Esse recurso é a base da tentativa de dar credibilidade ao texto jornalístico, em que o autor se posiciona de forma a criar um distanciamento linguístico dos fatos para parecer isento em sua narrativa.

Cabe destacar outro elemento importante, que é a descontração versus a formalidade, recursos que derivam do uso do vocabulário empregado para dar efeitos diferentes (intimidade, aproximação, imparcialidade, verdade etc.). Esse é outro elemento discursivo facilmente reconhecido nas programações radiofônicas, pois o meio busca identificação maior com os ouvintes por meio de uma linguagem mais próxima da "falada", são aceitos alguns desvios da língua culta à pretexto de facilitar o entendimento dos receptores. $O$ último traço apontado por Barros (2001) é a simetria ou a assimetria dos papéis dos atores no discurso, devendo ser desdobrados em três tipos: convencionais, sociais e pessoais.

Os procedimentos do discurso constroem diferentes papéis convencionais para os atores (entrevistador/entrevistado; expositor/debatedor; escritor/leitor etc.) e sociais, com ou sem desequilíbrios (professor/aluno; patrão/empregado; amigo/amigo etc.), e diferentes papéis pessoais ou de estilo, de modo a conduzir a interação (escolha de tópicos, manutenção ou não de turnos etc.) (BARROS, 2001, p. 70). Esses papéis podem ser identificados nos conteúdos jornalísticos a partir da leitura simples dos posicionamentos discursivos apresentados nas matérias, entrevistas, citações de informações veiculadas em uma emissora jornalística.

\section{Considerações finais}

Cabe destacar que a distinção rígida entre fala e escrita não se sustenta do ponto de vista dos atores, assim como no espaço e no tempo, levando a considerarmos posições intermediárias em todos os aspectos mencionados. 


\section{$\hat{A N}[\odot R A$}

\section{Alvaro Bufarah JÚNIOR}

Em suma, podemos indicar que língua e fala são definidas por um conjunto de elementos que, muitas vezes, não estão presentes nos usos linguísticos; o que se tem de fato são posições intermediárias entre a "língua" e a "fala", estabelecendo assim modos e formas diversas de produzir sentidos e de constituir relações entre os sujeitos, situação que pode ser registrada ao avaliarmos as diversas formas (entonação, linguagem, locução etc.) apresentadas se comprarmos a divulgação de uma mesma notícia por programas diferentes em emissoras distintas. Os produtores de conteúdo buscam adaptar seus textos às características de suas audiências, levando a uma variação linguística diversificada ao narrarem o mesmo fato.

A estrutura do texto locutado, no meio rádio, era baseada no roteiro impresso em laudas. A linguagem era de um texto escrito para ser "falado" pelos apresentadores de tal forma a lembrar a interação de uma conversa. Para tanto, o texto era composto com marcas do discurso de um diálogo em tempo real do locutor com os ouvintes. Com o impacto das tecnologias de comunicação, a linguagem passou a ser menos lida e mais improvisada em uma conversa entre o apresentador e os ouvintes, baseadas nos materiais que são acessados pelo jornalista no estúdio da emissora.

O efeito de imparcialidade ou parcialidade, dependendo da aproximação ou distanciamento do enunciatário para com o discurso, ainda é a base da tentativa de dar credibilidade ao texto jornalístico, em que o autor se posiciona de forma a criar um distanciamento linguístico dos fatos para parecer isento em sua narrativa. Com o uso das redes sociais, deslocamos o sentido de verdade, que antes estava nas falas das fontes (especialistas, pesquisadores, testemunhas etc.) e dos repórteres, para as múltiplas vozes que ressoam pelo WhatsApp e demais redes sociais. Podemos afirmar que o discurso do radiojornalismo mudou para agregar novas vozes, mas mantém o controle ideológico e operacional dos processos de veiculação. Como resultado, as narrativas dos radiojornais foram deslocadas para uma nova estrutura de 
modulação mais próxima da fala de improviso, distanciando-se da fala estruturada nos roteiros, escrita para ser verbalizada pelos locutores. Esse processo adequa-se melhor à torrente de informações que chega aos monitores computacionais dos apresentadores a cada minuto, impossibilitando a restruturação das notícias em roteiros previamente organizados e minuciosamente trabalhados para terem uma ordem de apresentação justificada pela priorizadas das informações em blocos de editorias. Após a introdução dos novos conceitos de comunicação baseados na digitalização, os temas são escolhidos pela relevância momentânea, sendo possível o surgimento, nos minutos seguintes, de outros acontecimentos mais interessantes para serem veiculados.

A caracterização desse processo de produção está na articulação das informações seguindo a lógica de prioridades dos sites das agências de notíáas na web. Os demais meios de comunicação passaram a interagir com esse novo tempo de publicação, deixando de lado a checagem dos dados, algo que era fundamental nos antigos radiojornais. A velocidade de veiculação precede a natureza dos próprios fatos narrados. Com o pretexto da velocidade, alteramos as narrativas jornalísticas no rádio buscando maior audiência, mas acabamos por fragilizar os processos de apuração das informações. Ao somarmos isso a uma linguagem mais informal e focada em nichos de audiência, temos uma nova realidade, com narrativas enxutas, construídas de forma rápida e não reflexiva, dando status de verdade a informações produzidas por pessoas não identificadas em condições também desconhecidas. Com isso, ampliamos a interação com os ouvintes, mas perdemos a qualidade dos dados apresentados, ferindo os conceitos basais do radiojornalismo como um produto sociocultural diferenciado, como apresentado por Meditsch (1999). O radiojornalismo precisa buscar novas formas de entendimento do cenário tecnológico e seus desdobramentos para produzir conteúdos realmente diferenciados, voltando a ter mais protagonismo no cotidiano dos ouvintes,

João Pessoa - Brasil | ANO 7 VOL. 7 N. 1 | JAN./JUN. 2020 | p. 87-104 


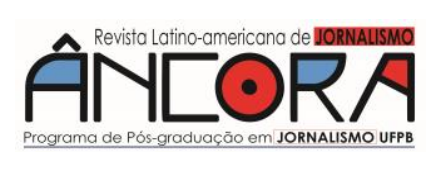

\section{Alvaro Bufarah JÚNIOR}

evitando a colagem de materiais originados nas redes sociais, sites e demais fontes, dando valor às entrevistas e ao trabalho dos repórteres e produtores. Desta forma, diferenciando o conteúdo e o ato da escuta, levando a qualificação da audiência e cumprindo seu papel social como meio de comunicação.

\section{Referências}

BALSEBRE, Armand. El lenguaje radiofónico. Madrid: Cátedra, 1994. BARROS, Diana Luz Pessoa de. Entre a fala e a escrita: algumas reflexões sobre as posições intermediárias. In: PRETI, D. (Org.). Fala e Escrita em questão. 2. ed. São Paulo: Humanitas: FFLCH/USP, 2001. p. 57-78. (Projetos Paralelos, NURC/SP, v. 4). BARROS, Diana Luz Pessoa de. Teoria semiótica do texto. 5. ed. São Paulo: Ática, 2011.

FAUS BELAU, Angel. La radio, introduccion a um médio desconocido. Madri: Editora Latina, 1981.

FIORIN, Jose Luiz. Elementos de análise do discurso. 15. ed. São Paulo: Contexto, 2013.

HAUSMAN, Carl; MESSERE, Fritz; O'DONNEL Lewis; BENOIT, Phillip. Rádio: produção, programação e performance. Tradução Marleine Cohen. Revisão técnica Alvaro Bufarah. São Paulo: Cengage Learning, 2010.

MEDITSCH, Eduardo Viana. A Rádio na era da informação. Coimbra: Minerva Editora, 1999.

NEIVA, Eduardo. Dicionário Houaiss de comunicação e multimídia. São Paulo: Publifolha: Instituto Antonio Houaiss, 2013.

ORTRIWANO, Gisela Swetlhana. A Informação no rádio: os grupos de poder e a determinação dos conteúdos. 2. ed. São Paulo: Summus, 1985. ORTRIWANO, Gisela Swetlhana. Radiojornalismo no Brasil: fragmentos de história. Revista USP, n. 56, p. 66-85, 2003. Disponível em:

<http://www.revistas.usp.br/revusp/article/view/33808>. Acesso em: 27 jul. 2017.

SILVA, Fernando Firmino da. Jornalismo e tecnologias da mobilidade: conceitos e configurações. In: SIMPÓSIO NACIONAL DE PESQUISADORES EM CIBERCULTURA - ABCIBER, 2. São Paulo, 2008. Anais... São Paulo: ABCIBER, 2008.

SILVA, Júlia de Oliveira Albano da. Rádio: oralidade mediatizada - o spot e os elementos da linguagem radiofônica. São Paulo: Annablume, 1999. 